NASA TECHNICAL MEMORANDUM 104132

$$
\begin{array}{r}
1 N-24 \\
33463 \\
p 3^{2}
\end{array}
$$

\title{
CONSTANT AMPLITUDE AND POST- OVERLOAD FATIGUE CRACK GROWTH BEHAVIOR IN PM ALUMINUM ALLOY AA 8009
}

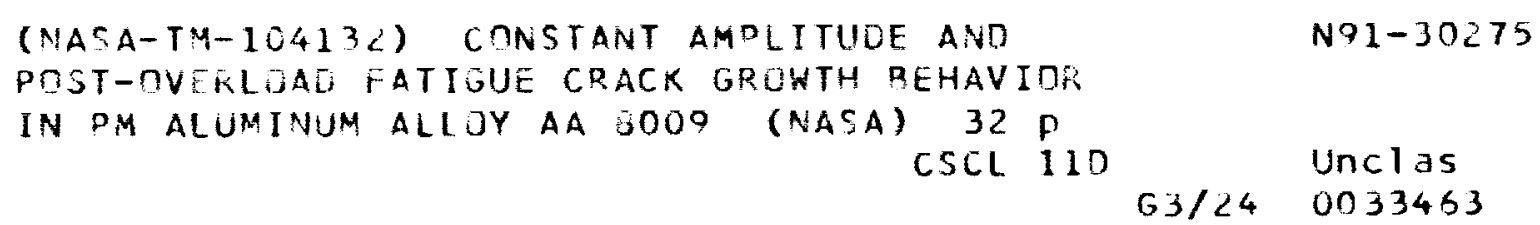

A. P. Reynolds

AUGUST 1991

N/SA

National Aeronautics and

Space Administration

Langley Research Center

Hampton, Virginia 23665-5225 



\title{
CONSTANT AMPLITUDE AND POST-OVERLOAD FATIGUE CRACK GROWTH BEHAVIOR IN PM ALUMINUM ALLOY AA 8009
}

\author{
A. P. Reynolds \\ NRC Associate, NASA Langley Research Center, \\ MS 188E, Hampton, VA, U.S.A.
}

\begin{abstract}
A recently developed, rapidly solidified, powder metallurgy, dispersion strengthened aluminum alloy, AA 8009, was fatigue tested at room temperature in lab air. Constant amplitude/constant $\Delta \mathrm{K}$ and single spike overload conditions were examined. High fatigue crack growth rates and low crack closure levels compared to typical ingot metallurgy aluminum alloys were observed. It was proposed that minimal crack roughness, crack path deflection, and limited slip reversibility, resulting from the ultra-fine microstructure, were responsible for the relatively poor da/dN- $\Delta \mathrm{K}$ performance of AA 8009 as compared to that of typical IM aluminum alloys.
\end{abstract}

\section{Nomenclature}

$\mathrm{a}_{\text {aff }}$ - overload affected crack length.

$\mathrm{B}$ - specimen thickness (mm).

$\mathrm{da} / \mathrm{dN}$ - crack growth rate on a per cycle basis.

E - Young's Modulus (GPa).

$\mathrm{e}_{f}$ - elongation to failure/specimen gage length.

$\mathrm{K}_{I C}$ - critical plane strain stress intensity factor.

$\mathrm{K}_{\max }$ - maximum stress intensity factor.

$\mathrm{K}_{o l}$ - overload stress intensity factor.

$\mathrm{K}_{o p}$ - crack opening stress intensity factor.

$\mathrm{N}_{D}$ - post-overload delay cycles.

$P_{o p}$ - crack opening load.

$\mathbf{R}$ - stress ratio, minimum/maximum.

$r_{o l}$ - overload plastic zone size.

$\alpha$ - constraint factor.

$\Delta \mathrm{K}$ - cyclic stress intensity factor (MPa $/ \mathrm{m})$.

$\Delta \mathrm{K}_{B}$ - baseline cyclic stress intensity factor.

$\Delta \mathrm{K}_{e f}$ - closure corrected cyclic stress intensity factor.

$\sigma_{u}$ - ultimate strength.

$\sigma_{y s}$ - yield strength. 


\section{INTRODUCTION}

Several rapidly solidified (RS), powder metallurgy (PM), dispersion strengthened aluminum alloys have recently been developed in an attempt to increase the service temperatures of aluminum alloys for use in applications where expensive and comparatively heavy materials such as titanium alloys are currently used. These PM aluminum alloys typically exhibit good microstructural stability at temperatures as high as $450^{\circ} \mathrm{C}$ with consequent retention of room temperature strength after exposure at elevated temperature $[1,2]$. While the monotonic properties of this class of alloys are both stable and good after high temperature exposure, in order to be technologically useful they must also exhibit adequate fatigue crack growth resistance and damage tolerance. At present, little is known of the fatigue properties of these PM dispersion strengthened alloys. The behavior of these alloys under fatigue loadings at both room and elevated temperatures must be understood before they can be incorporated into high temperature aircraft structures.

It has previously been observed that while the strength, stress corrosion resistance and toughness of PM aluminum alloys may be equivalent or superior to those of comparable ingot metallurgy (IM) alloys, their fatigue crack growth properties are generally inferior[3]. This paper presents an investigation of the factors governing the fatigue crack growth properties of AA 8009 at room temperature in lab air. AA 8009 is a dispersion strengthened alloy produced by Allied Signal Corporation which exhibits a combination of strength, tensile modulus and ductility comparable to many ingot metallurgy aluminum alloys (see table 1). In addition, these properties are retained after exposure at temperatures as high as $450^{\circ} \mathrm{C}[2]$. The alloy has a nominal composition of $\mathrm{Al}-8.0 \mathrm{Fe}-1.0 \mathrm{~V}-2.0 \mathrm{Si}$. It is produced via a planar flow casting technique 
which results in an extremely fine grain structure (typical grain size is approximately 0.5 micron) stabilized and strengthened by 27 volume $\%$ of spherical, $\mathrm{Al}_{12}(\mathrm{Fe}, \mathrm{V})_{3} \mathrm{Si}$ dispersoids. The dispersoid diameter is 40 to $80 \mathrm{~nm}[4]$.

AA 8009 exhibits a flat fatigue fracture surface and straight crack path due to its very fine scale and homogeneous microstructure. The fatigue fracture surface morphology of AA 8009 will allow an examination of the role of plasticity induced closure in fatigue crack growth while minimizing the complicating factors of crack surface roughness and crack path tortuosity. Crack tip closure levels were examined using near crack tip transverse strain gages[5,6]. The near crack tip closure measurements may provide a more accurate picture of the closure occurring at the crack tip than traditional far-field methods such as crack mouth opening gages and back face strain gages[7,8]. Both steady state (constant load amplitude and constant $\Delta \mathbf{K}$ ) and transient (due to single spike overload) crack growth were studied.

\section{EXPERIMENTAL PROCEDURE}

The product forms used in this study were $6.4 \mathrm{~mm}$ and $3.2 \mathrm{~mm}$ thick plate. Compact tension specimens of L-T orientation were tested. The specimens were of standard design[9] (see fig. 1) with $\mathrm{W}=50.8 \mathrm{~mm}$ and $\mathrm{B}=6.4 \mathrm{~mm}, 3.2 \mathrm{~mm}$ and $1.5 \mathrm{~mm}$ (produced by grinding 3.2 $\mathrm{mm}$ thick plate). Compact tension specimens, $6.4 \mathrm{~mm}$ thick with $20 \%$ side-grooves $\left(\mathrm{B}_{\text {net }} / \mathrm{B}_{\text {gross }}=0.8\right)$ were also tested in order to assess the influence of the plane stress surface regions of the specimens on fatigue crack propagation rate. Fatigue crack growth experiments were performed using a closed loop, servo-hydraulic test machine operated in load control. Constant load and constant $\Delta \mathrm{K}$ with and without single spike overload tests were performed. Constant $\Delta \mathrm{K}$ tests were performed at load ratios (R) of 0.1 and 0.7 . During the constant $\Delta \mathrm{K}$ 
tests, $5 \%$ load sheds were performed in such a manner as to prevent deviations from the target $\Delta \mathrm{K}$ of greater than $2.5 \%$. Crack length was measured optically on both sides of the specimens and the average surface crack length was used for determination of stress intensity factor and crack growth rate. Crack lengths were measured with a precision of $0.01 \mathrm{~mm}$. Adhesively bonded, transverse strain gages were used to monitor closure loads during selected load sequences[5,6]. The strain gages were placed on the specimen side face so that the crack tip was within $\approx 1 \mathrm{~mm}$ of the gage with the gage grid perpendicular to the loading axis.

Single spike overload tests were performed such that all overload stress intensity factor levels $\left(\mathrm{K}_{o l}\right)$ were equal to twice the $\mathrm{K}_{\max }$ of the corresponding constant $\Delta \mathrm{K}$ (the baseline $\Delta \mathrm{K}$ or $\Delta \mathrm{K}_{B}$ ), this was termed a $100 \%$ overload. In order to provide a direct comparison for AA 8009 , the behavior of AA 2618-T651 under single spike overload conditions was also studied. 2618 specimens were single edge notch tension. AA 2618 is a wrought ingot metallurgy alloy (equiaxed grains, 40 micron diameter) developed for service temperatures greater than those of typical IM alloys. The nominal composition of 2618 is $\mathrm{Al}-2.3 \mathrm{Cu}-1.6 \mathrm{Mg}-1.1 \mathrm{Fe}-1.0 \mathrm{Ni}-0.18 \mathrm{Si}-$ $0.07 \mathrm{Ti}$.

\section{RESULTS}

\section{Constant Amplitude / Constant $\Delta \mathrm{K}$ Fatigue Crack Growth}

Figure 2 shows the results of constant load amplitude and constant $\Delta \mathrm{K}$ fatigue crack growth tests performed on compact tension specimens of the three thicknesses, including sidegrooved $6.4 \mathrm{~mm}$ thick compact tension specimens. The results indicate that the effect of specimen thickness (over the range tested) on steady state fatigue crack growth rates at $\Delta \mathrm{K}$ 's between 5.5 and $25 \mathrm{MPa} \vee \mathrm{m}$ was not great, although the thinnest specimen, $1.5 \mathrm{~mm}$, did exhibit 
somewhat reduced $\mathrm{da} / \mathrm{dN}$ at $\Delta \mathrm{K}>10 \mathrm{MPa} \vee \mathrm{m}$. This observation is consistent with increased plasticity induced closure resulting from greater levels of plane stress behavior, for a given $\Delta \mathrm{K}$, in thinner specimens. Closure levels are more influenced by the plane stress surface regions, as the ratio of plastic zone size to specimen thickness becomes greater. The plane stress plastic zone may be several times larger than the plane strain plastic zone[10]. This larger plastic zone may give rise to higher levels of plasticity induced closure and consequently, lower $\Delta \mathbf{K}_{e f}$ and lower $\mathrm{da} / \mathrm{dN}$.

As is shown in figure 2, fatigue crack growth rates in AA 8009 at $R=0.1$ are lower than rates at $R=0.7$ but the differences are small. Also indicated in figure 2 is a scatter-band (dashed-lines) for high R ( $>0.75$; assumed closure free) data for ingot metallurgy (IM) aluminum alloys[11]. All of the data for AA 8009 (both low and high R) falls either inside or slightly above this scatter-band, suggesting that intrinsic or closure free crack growth rates in AA 8009 are similar to, but slightly greater than; typical ingot metallurgy alloy intrinsic crack growth rates. The greatest difference in crack growth rates between 8009 and typical IM alloys is observed at low $\Delta \mathrm{K}$. The observation that $\mathrm{R}$ effects on da/dN in 8009 are small implies that extrinsic factors, such as crack closure, have a minimal beneficial effect on low $R \mathrm{da} / \mathrm{dN}$ in AA 8009. Typical low R crack growth rates for most IM aluminum alloys e.g. 2024-T3 or 2090 , would be considerably below their corresponding high $\mathrm{R}$ rates and well below comparable $8009 \mathrm{R}=0.1$ crack growth rates[12].

Figure 3 compares typical load (normalized by maximum load) against reduced strain traces produced for alloys 8009 and 2618-T651 (a wrought, ingot metallurgy, aluminum alloy for elevated temperature use). Reduced strain is determined by subtracting the linear elastic 
strain from the total strain, making non-linearity in the load-strain behavior more apparent. Both traces were obtained at $\Delta \mathrm{K}=8.8 \mathrm{MPa} V \mathrm{~m}$ and $\mathrm{R}=0.1$. The load at which the reduced strain signal exhibits a sharp deviation from linearity is believed to be the crack opening load $\left(\mathrm{P}_{\text {op }}\right)$ which corresponds to the crack opening stress intensity $\left(K_{o p}\right)[5,6]$. The reason for the different directions on the "tails" of the normalized load against reduced strain traces in figure 3 is unknown but may be a result of the position of the crack tips relative to the strain gage grids. Measured $\mathrm{K}_{o p}$ during constant $\Delta \mathrm{K}$ loading of AA 8009 at $\mathrm{R}=0.1$ was between 0.25 and 0.3 of $\mathrm{K}_{\max }$ at a baseline $\Delta \mathrm{K}$ of $8.8 \mathrm{MPa} V \mathrm{~m}$. This level of closure corresponds to a $\Delta \mathrm{K}_{e f f}$ equal to between $80 \%$ and $85 \%$ of the applied $\Delta \mathrm{K} ; \Delta \mathrm{K}_{e f f}=\mathrm{K}_{\max }-\mathrm{K}_{o p}$. Alloy 2618-T651, on the other hand, exhibits a $\Delta \mathrm{K}_{e f f}$ equal to only about $60 \%$ of the applied $\Delta \mathrm{K}$ under similar loading conditions. Opening K's in 2024 [13] under similar loading conditions have been measured and are similar to the levels found for 2618. The higher opening K's (compared to those of 8009) found in most ingot metallurgy aluminum alloys are indicative of the large role that crack closure plays in determining the crack growth rates at low $\mathrm{R}$ in these alloys.

AA 8009 fatigue fracture path deflection and fracture surface roughness are minimal compared to most IM aluminum alloys. Figures $4 \mathrm{a}$ and $4 \mathrm{~b}$ compare the fatigue fracture surfaces in AA 8009 and $\mathrm{AA} 2618$ at $\Delta \mathrm{K}=8.8 \mathrm{MPa} V \mathrm{~m}$. In addition to the low roughness (qualitatively confirmed by stereo-microscopy) exhibited by 8009 fatigue fracture surfaces at both high and low $\Delta \mathrm{K}$, no apparent change in fracture mode is observed between the high and low $\Delta \mathrm{K}$ regions and crack roughness is lower at low $\Delta \mathrm{K}$ than at high $\Delta \mathrm{K}$. While crack growth rates in 8009 begin to show some deviation from Paris law behavior at $\Delta \mathrm{K}$ approaching 1.1 $\mathrm{MPa} \vee \mathrm{m}$, the rates do not exhibit the rapid reduction at low $\Delta \mathrm{K}$ which typifies the behavior of 
most ingot metallurgy alloys at low $\Delta \mathrm{K}$. The absence of true threshold behavior at crack growth rates down to $\approx 10^{-10} \mathrm{~m} /$ cycle at $\Delta \mathrm{K}=1.1 \mathrm{MPa} / \mathrm{m}$ may be related to the decreasing crack surface roughness and increasingly straight crack path exhibited by 8009 at low $\Delta \mathrm{K}$. Single Spike Overload Behavior

The response of 8009 to the application of single spike overloads is similar to the response of other aluminum alloys. Increased number of delay cycles are observed at high and low values of the ratio of calculated overload plastic zone size, $r_{o l}$, to specimen thickness, $B$. This is shown in figure 5, which is a plot of delay cycles $\left(\mathrm{N}_{d}\right)$ against $\mathrm{r}_{o l} / \mathrm{B}$ for 8009 and data for other alloys taken from the literature. The range of $r_{o l} / B$ for 8009 was obtained by performing overloads at various $\Delta \mathrm{K}_{B}$ on specimens with B's ranging between 1.6 and $6.4 \mathrm{~mm}$. The dashed curves in figure 5 are visual fits.

Several authors have reported that a plot of delay cycles, $\mathrm{N}_{D}$, against $\mathrm{r}_{o l} / \mathrm{B}$ results in a "U" shaped curve $[14,15,16]$. The shape of the curve has been explained in the following manner: At $\mathrm{r}_{o l} / \mathrm{B} \approx 1$, triaxial constraint is lost and the material undergoes plane stress deformation. Plane stress deformation results in a large plastic zone (due to reduced yield strength resulting from loss of constraint) which leads to high closure loads and a large affected crack length which in turn results in large numbers of delay cycles. At low $\mathrm{r}_{o l} / \mathrm{B}$, generally corresponding to low $\Delta \mathrm{K}_{B}$, increased delay results from rising closure loads, resulting from the overload, decreasing the effective $\Delta \mathrm{K}$ to a level near the threshold $\Delta \mathrm{K}$. In the near threshold crack growth region, a small reduction in $\Delta \mathrm{K}$ results in a larger reduction in $\mathrm{da} / \mathrm{dN}$ than in the Paris law region; therefore, overloads which cause $\Delta \mathrm{K}_{e f f}$ to approach the threshold $\Delta \mathrm{K}$ result 
in large delays. It can be seen in figure 5 that $N_{D}$ for $100 \%$ overloads in 8009 is lower at all $\mathrm{r}_{o} / \mathrm{B}$ than $\mathrm{N}_{D}$ for either 2024-T351 [17] or 2090-T8E41[16].

It has also been observed that retarded fatigue crack growth does not always begin immediately upon application of a single spike overload (delayed retardation), and that typically, the slowest post overload fatigue crack growth occurs after the crack has grown a distance of between 0.2 and 0.4 times the overload affected crack length[15-19] It has been previously observed that the overload affected crack length is typically of the same order as the overload plastic zone size[18] which may be determined from the following equation[20]:

$$
\mathrm{r}_{o l}=\pi / 8\left(\mathrm{~K}_{o l} / \sigma_{y s}\right)^{2}
$$

Figure 6 illustrates the crack growth rates through overload plastic zones for a number of baseline $\Delta K$ 's and $100 \%$ overloads in 8009 and 2024-T3 [16]. The crack growth rates are normalized by the rates at the corresponding $\Delta \mathrm{K}_{B}$ and the distances are normalized by the respective affected crack lengths (affected crack length, $a_{a f f}$, is defined as the length which the crack must grow after an overload before baseline crack growth rates are reestablished). Figure 6 shows that the overload behavior of alloy 8009 exhibits features typical of overload behavior in other aluminum alloys as described above. Alloy 8009 exhibits delayed retardation and the minimum post-overload crack growth rate occurs at approximately the same position in the overload affected zone in 8009 as in 2024-T3. The solid line in figure 6 is a prediction from Newman's FASTRAN program[21] which models post overload crack growth on the basis of plasticity induced closure considerations and a constraint factor, $\alpha$, which is determined from constant amplitude $\mathrm{da} / \mathrm{dN}-\Delta \mathrm{K}$ data generated at $\mathrm{R}=0.1$ and 0.7 and is dependent on fatigue crack growth rate. The 8009 behavior was modeled using an $\alpha$ of 2.4 for crack growth rates 
below $10^{-7} \mathrm{~m} /$ cycle and 1.8 for rates above $3.6 \times 10^{-6} \mathrm{~m} /$ cycle. Alpha is determined by linear interpolation between the two transition crack growth rates[23]. It can be seen in figure 6 that the behavior predicted by the model is similar to that observed experimentally. It can also be seen in figure 6 that the minimum normalized crack growth rate for the IM 2024-T3 alloys is similar to that of 8009 . From a comparison of literature data[16] with 8009 constant amplitude crack growth results it was determined that steady state crack growth rates are much lower in 2XXX series IM alloys and somewhat lower in $7 \mathrm{XXX}$ series IM alloys. Therefore, the minimum crack growth rates resulting from overloads in AA 8009 are higher than those experienced by typical IM alloys under similar loading conditions.

In figures $7 \mathrm{a}$ and $7 \mathrm{~b}$, the differences between the appearance of overloads on the surfaces of 8009 and 2618-T651 fatigue specimens are illustrated. Alloy 2618 exhibits a highly branched and tortuous crack path, and in some cases extensive crack bifurcation occurs on overloading. In alloy 8009 , the only obvious effect of the overload is curving of the crack path which results from a change in the size of the shear lip. As the crack grows through the overload zone (at a rate lower than the steady state, baseline rate), the size of the shear lip is decreased and the crack front tends to flatten out. As the crack reaches the end of the overload affected region, and re-establishes its baseline crack growth rate, the shear lip regains its steady state size.

The number of delay cycles resulting from application of $100 \%$ overloads at a $\Delta \mathrm{K}_{B}$ of 8.8 $\mathrm{MPa} V \mathrm{~m}$ in 2618-T651 was greater than the number resulting from identical overloads applied to 8009 . Delays in 2618 averaged 10,500 cycles while in 8009 the delays were typically 6000 cycles. In selected cases, near-crack tip, side face strain gages were used to 
monitor crack opening loads while the cracks grew through overload zones. Plotted in figures 8 and 9 are post-overload crack growth rates normalized by baseline $(\Delta \mathrm{K}=8.8 \mathrm{MPa} / \mathrm{m})$ crack growth rates and crack opening loads normalized by maximum loads for 2618 and 8009 respectively. Also plotted in fig. 9 is a dashed line representing opening load against postoverload crack growth predictions from the FASTRAN model. The normalized loads and crack growth rates are plotted against the distance from the point of overload application divided by the affected crack length.

In alloy 2618 the correlation between rate and opening load is good all the way to the end of the overload affected region where the re-establishment of the steady state crack growth rate corresponds closely to the point where opening loads revert to their baseline value. While post-overload opening loads in 8009 correlate well with crack-growth rates up to a point just beyond that where the minimum crack growth rate was measured, beyond that point the correlation is less good. As can be seen in figure 9, the opening loads remain above their steady state value for some distance beyond the point where steady state crack growth rates are re-established. The FASTRAN model prediction correlates very well with the post overload crack growth rates. Although the correlation between the observed crack opening loads and the observed post-overload crack growth rates is not perfect, overall, the evidence indicates that $\mathrm{da} / \mathrm{dN}$ through the overload zone is controlled primarily by $\Delta \mathrm{K}_{e f}$ as measured by the side face strain gage. 


\section{DISCUSSION and INTERPRETATION}

\section{Paris Regime Crack Growth and Overload Behavior}

It appears from the results presented here that the primary factor differentiating the fatigue crack growth behavior of 8009 from that of a variety of ingot metallurgy aluminum alloys is the comparatively low level of fatigue crack closure present in alloy 8009 . Closure levels measured in alloys 2618 and 8009 indicate that opening loads in the $\mathrm{IM}$ alloy are much higher than in 8009. Literature values for opening loads in 2024-T351 indicate that opening loads in that alloy are high compared to 8009 as well[13]. Crack growth rate data at $R=0.1$ and $\mathrm{R}=0.7$ for 8009 also indicate a very small $\mathrm{R}$ effect and therefore a minor influence of closure on fatigue crack growth rates in the PM alloy.

There are three mechanisms commonly proposed for fatigue crack closure: plasticity induced closure, roughness induced closure, and oxide induced closure[22]. Oxide induced closure can probably be ignored for tests conducted at room temperature in lab air as no oxide fretting was observed on 8009 fracture surfaces. Considering IM alloys 2618-T651, 2024T351, and 2090-T8 and PM alloy 8009 (the four alloys for which overload delay data were presented), there does not appear to be any reason why they should exhibit varying behavior on the basis of plasticity induced closure only. An analytical fatigue crack growth model incorporating closure (due to Newman) requires tensile properties and an experimentally determined constraint factor as material property inputs; on the basis of the tensile properties all of the alloys being considered would exhibit similar levels of plasticity induced closure[21]. On the other hand, crack surface roughness is minimal in 8009 and roughness induced closure 
could be nearly absent in 8009 and could have a progressively more dominant effect on fatigue crack growth rates in 2024-T351 and 2090-T8.

Progressively higher levels of roughness induced closure in 8009, 2024-T351 and 2090T8 could account for the relative amounts of post-overload delay shown in figure 6 . Examination of 2024-T351 fracture surfaces indicates that they are significantly rougher than 8009 fracture surfaces and it is generally acknowledged in the literature that alloy 2090 exhibits very high crack surface roughness[11,16]. Alloy 2618-T651, which also exhibits a rough fracture surface morphology, experiences significantly larger delays due to $100 \%$ overloads at $\Delta \mathrm{K}_{B}=8.8 \mathrm{MPa} / \mathrm{m}$ than does 8009 . Variations in fatigue crack surface roughness readily correlate differences in the fatigue crack growth behavior of the alloys discussed above. A similar effect of crack surface roughness has also been observed in steels[24].

\section{Microstructural Effect on Low $\Delta K$ Crack Growth}

PM alloy 8009 and typical ingot metallurgy aluminum alloys exhibit significant differences in the establishment of a fatigue threshold, which may be partially accounted for by differences in crack surface roughness. Alloy 8009 does not appear to exhibit threshold behavior at cyclic stress intensity levels down to $1.1 \mathrm{MPa} \vee \mathrm{m}$ and $\mathrm{R}=0.1$. Typical low $\mathrm{R}$, ingot metallurgy alloy threshold $\Delta \mathrm{K}$ 's fall in the range of 2.5 to $4 \mathrm{MPa} / \mathrm{m}[25]$. As threshold $\Delta \mathrm{K}$ levels are approached in lab air tests, IM alloys normally exhibit a fracture mode transition from a striated growth mechanism to one of crystallographic crack advance[16,26]. In some cases the high $\Delta \mathrm{K}$ fracture mode may be one of slip band cracking and or intersubgranular cracking as in 2090[27]. In any case, the near threshold, crystallographic crack growth typically results in a highly deflected crack path and a rough crack surface[22]. 
In ingot metallurgy alloys, near threshold cyclic plastic zone sizes are less than the grain size. This can result in crack tip deformation by shear on a single slip system, promoting mode $\Pi$ displacements and consequent premature contact of fracture surface asperities which in turn leads to higher closure loads and reduced $\Delta \mathrm{K}_{e f f}$ Low $\Delta \mathrm{K}$ crack growth in 8009 , on the other hand does not result in any observable change in fracture mode although the crack path becomes straighter and the surface smoother. That a low $\Delta \mathrm{K}$ fracture mode change was not observed in alloy 8009 may be attributable to the ultra-fine grain structure of 8009 (i.e. fracture surface features indicative of a fracture mode change would be small and difficult to observe), but even in the event that a fracture mode change does occur, there is no accompanying increase in fracture surface roughness. Changes in fracture mode near threshold have been attributed to the cyclic plastic zone size being less than some microstructural dimension, e.g. the grain or subgrain size[28]. In order for the cyclic plastic zone to be completely within one grain of $8009, \Delta \mathrm{K}$ must be well below $1.6 \mathrm{MPa} \vee \mathrm{m}$ or less than the threshold $\Delta \mathrm{K}$ of most IM aluminum alloys[29].

The fine grain microstructure of 8009 may affect its low $\Delta \mathrm{K}$ crack growth behavior relative to large grain IM alloys in a number of ways. As described above, low $\Delta \mathrm{K}$ fracture mode changes in IM alloys are believed to be a result of a cyclic plastic zone sizes below some critical microstructural length. Below this critical plastic zone size, deformation via slip on a single crystallographic slip system, i.e. single slip, may occur, resulting in crystallographic crack advance and mode two crack tip displacements. One can envision differences in this process in large and small grain materials. Consider for example equal mode II displacements imposed on crack tips in a large and a small grain material. At low $\Delta \mathrm{K}$ it will be assumed that 
all of the displacement occurs within a single grain (otherwise the conditions for the fracture mode transition will not be met). Assuming this, one can calculate a strain, which may be approximated by the mode II displacement divided by the grain size. Obviously, in a small grain material, this strain will be larger than in a large grain material. Compatibility requires that shape changes (strains) in one grain be accommodated by surrounding grains and this generally requires the activation of multiple slip systems at grain boundaries. (It has been shown that polycrystals, not necessarily fine grain, deforming primarily by single slip in grain interiors, deform by multiple slip near grain boundaries[30]). It is easy to see that in a very fine grain material, e.g. 8009, where all of the material is near the grain boundary, activation of multiple slip near the boundaries will result in multiple slip throughout the grain; hence, there will be minimal mode II displacement and minimal crystallographic crack advance. Without the fracture surface asperities produced by crystallographic crack advance, and without the mode II crack tip displacements brought about by single slip, no increase in closure loads due to increased roughness induced closure is experienced at low $\Delta \mathrm{K}$, and Paris regime crack growth behavior is observed at low $\Delta \mathrm{K}$ 's.

Aside from the inhibition of roughness induced closure resulting from suppression of single slip in fine grain materials, there may also be an effect on slip reversibility resulting from activation of multiple slip. In materials deforming by single slip, cross slip and dislocation intersection may be minimal. In this case, slip will be to some extent reversible, that is; tensile strain and compressive strain in the cyclic plastic zone may be accomplished by movement of the same dislocations. In a material in which multiple slip systems have been activated, dislocation intersection and reactions may greatly inhibit slip reversibility resulting 
in more rapid accumulation of damage in the cyclic plastic zone; that is, new dislocations will have to be generated on each forward and reverse cycle in order to accommodate the cyclic strain. This efficient accumulation of damage will contribute to higher crack growth rates in materials deforming by multiple slip than in materials undergoing single slip deformation[31]. Such a difference in slip reversibility between coarse and fine grain materials may be a contributing factor to the comparatively high crack growth rates observed in 8009 at low $\Delta \mathrm{K}$. An inhibition of slip reversibility resulting in more efficient damage accumulation would constitute a reduction in intrinsic crack growth resistance.

It should be noted that while low roughness and inhibition of slip reversibility do provide a possible explanation of the observed low $\Delta \mathrm{K}$ crack growth rates in 8009 , the rates may also be explainable on the basis of an environmental interaction. Water vapor in the lab air environment may promote comparatively rapid crack advance along grain boundaries or crystallographic cleavage planes (unlikely because of the fine grain size) via a hydrogen embrittlement mechanism. This has been observed in subgrain boundary cracking of AA 2090 [27]. Because of the extremely fine 8009 fracture surface features, it was not possible to make a determination of the crack path (i. e. trans-vs. intergranular). One feature of the $8009 \mathrm{da} / \mathrm{dN}$ behavior which suggests that the high crack growth rates at low $\Delta \mathrm{K}$ are not due to a hydrogen embrittlement phenomenon is that mean stress $(R)$ has a very small effect on the rates. It might be expected that elevated mean stress would exacerbate a hydrogen embrittlement crack growth mechanism by increasing the volume of material near the crack tip which is subject to high tensile stress. Examination of the possibility of an environmental effect on the low $\Delta \mathrm{K}$ crack 
growth rates will require fatigue threshold testing in vacuum or some other inert environment.

\section{SUMMARY AND CONCLUSIONS}

It has been found that under constant amplitude fatigue loading and after single spike

overloads PM aluminum alloy 8009 exhibits very low levels of crack closure conmpared to ingot metallurgy alloys (e.g. 2618). Alloy 8009 exhibits closure levels consistent with predictions from plane strain finite element models while closure levels observed in most IM aluminum alloys are indicative of behavior intermediate between plane stress and plane strain. The primary observable differences in the fatigue behavior of 8009 and the IM aluminum alloys discussed above are in the fracture surface roughness and the crack path tortuosity. In fact, for load history types where crack closure can be expected to exert a dominant influence on crack growth rates, e. g. low $\mathbf{R}$ constant amplitude and post-overload transient crack growth, relative crack surface roughness can be correlated with the observed differences in crack growth rates of 8009 and the IM alloys for which data is presented.

Several observations on the post-overload behavior indicate that while roughness levels may influence the magnitude of delay, plasticity induced closure determines whether and how delays occur. It was observed that normalized $\mathrm{da} / \mathrm{dN}$ through normalized overload zones were very similar for several aluminum alloys regardless of the length of delay or level of crack surface roughness. It was also found that, in 8009 and in several other alloys examined previously[14,15,16], minimum post-overload delay occurs at some intermediate $r_{o l} / B$, regardless of the crack surface roughness.

Speculation on the reasons for 8009 's high crack growth rates at low $\Delta \mathrm{K}$ has lead to the following tentative conclusions: 
1. The grain size of 8009 results in suppression of crystallographic crack advance and its concomitant crack path deflection and mode II displacement via two mechanisms:

a. $\Delta \mathrm{K}$ must be very low for the cyclic plastic zone to be contained within a single grain.

b. The ultra fine grain size promotes homogeneous deformation through activation of multiple slip systems, even at very low $\Delta \mathrm{K}$, because of compatibility requirements at the grain boundaries.

2. The homogeneous deformation resulting from the ultra fine grain size in 8009 may contribute to comparatively high, crack growth rates at low $\Delta \mathrm{K}$ through suppression of slip reversibility. A possible alternative explanation is an environmental interaction with the grain boundaries resulting in rapid crack advance.

\section{ACKNOWLEDGEMENTS}

I would like to thank Dr. J. C. Newman, Jr. for his prediction of overload delay, Dr. D. S. Dawicke for his help in performing the crack opening load measurements and Dr. R.S. Piascik for many helpful discussions. I would also like to thank Mr. Dick Royster of NASALaRC for the 8009 tensile data. 


\section{REFERENCES}

1. D. Raybould, (1988) Dispersion Strengthened Aluminum Alloys, eds. Y.-W. Kim and W. M. Griffith, TMS, Warrendale, PA, pp. 199-215.

2. J. A. Hawk, P. K. Mirchandani, R. C. Benn, (1988) Dispersion Strengthened Aluminum Alloys, eds. Y.-W. Kim and W. M. Griffith, TMS, Warrendale, PA, pp. 517-537.

3. Aluminum: Properties and Physical Metallurgy, (1984) J. E. Hatch, Ed., pp. 390-391, ASM, Metals Park, Ohio.

4. P. S. Gilman, and S. K. Das, (1987) "Rapidly Solidified Al Alloys for High Temperature/High Stiffness Applications", in PM Aerospace Materials '87, pp. 27.1-27.11; Metal Powder Report Conference, Luzern, November 2-4.

5. D. S. Dawicke, J. C. Newman, Jr. and A. F. Grandt, Jr., (1990) NASA TM \#102590, NASA Langley Research Center, Hampton, VA.

6. D. S. Dawicke, A. F. Grandt, Jr., and, J. C. Newman, Jr., (1990) Engineering Fracture Mechanics, vol. 36, no. 1, pp. 111-121.

7. D. L. Davidson, (1991) Engineering Fracture Mechanics, vol. 38, no. 6, pp. 393-401.

8. P. B. Aswath, S. Suresh, (1991) Met Trans A, vol. 22a, pp. 817-828.

9. 1984 Annual Book of ASTM Standards, vol. 3.01, Method E 647-83, pg. 711-731. ASTM, 1916 Race Street, Philadelphia, PA, 19103.

10. D. Broek, Elementary Engineering Fracture Mechanics, 4th edition, pg. 114, Martinus Nijhoff Publishers, Dordrecht, the Netherlands.

11. K. T. V. Rao, R. S. Piascik, R. P. Gangloff, and R. O. Ritchie, Aluminum Lithium Alloys V, eds. T. H. Sanders, Jr. and E. A. Starke, Jr., pp. 293-305, AIME, Warrendale, PA.

12. K. T. V. Rao, W. Yu, R. O. Ritchie, (1988) Met Trans A, vol. 19, pp. 549-561.

13. W. Elber, (1971) Damage Tolerance in Aircraft Structures, ASTM STP 486, ASTM, p.230.

14. R. S. Vecchio, R. W. Hertzberg and R. Jaccard, (1984) Fatigue of Engineering Mats. and Struct, vol. 7, no. 3, pp. 181-194.

15. A. J. McEvily and Z. Yang, (1990) Met Trans A, vol. 21A, pp. 2717-2727. 
16. K. T. Venkateswara Rao and R. O. Ritchie, (1988) Acta Met., vol. 36, no. 10, pp. 28492862.

17. W. J. Mills and R. W. Hertzberg, (1975) Engineering Fracture Mechanics, vol. 7, pp. 705-711.

18. E.F.J. vonEuw, R.W. Hertzberg, and R. Roberts, (1972) "Delay Effects in Fatigue Crack Propagation," Stress Analysis and Growth of Cracks, Proceedings of the 1971 National Symposium on Fracture Mechanics, Part 1, ASTM STP 513, American Society for Testing and Materials, pp. 230-259.

19. N. Raganathan, J. Petit, and B. Bouchet, (1979) Engineering Fracture Mechanics, vol. 11, pp. 775-789.

20. D. Broek, Elementary Engineering Fracture Mechanics 4th ed., p. 104, Martinus Nijhoff Publishers, Dordrecht, the Netherlands.

21. J. C. Newman, Jr., (1981) "A Crack Closure Model for Predicting Fatigue Crack Growth under Aircraft Spectrum Loading", ASTM STP 748, J. B. Chang and C. M. Hudson, Eds., ASTM, pp. 53-84.

22. R. O. Ritchie, S. Suresh, (1982) Met Trans A, vol. 13a, pp. 937-940.

23. J. C. Newman, Jr., M. H. Swain and E. P. Phillips, (1986) "An Assessment of the Small Crack Effect for 2024-T3 Aluminum Alloy", in Small Fatigue Cracks, R. O. Ritchie and J. Lankford eds., TMS-AIME.

24. V. B. Dutta, S. Suresh, and R. O. Ritchie, (1984) Met Trans A, vol. 15, pg. 1193.

25. K. T. Venkateswara Rao, and R. O. Ritchie, (1989) Materials Science and Technology, vol.5, pp. 896-907.

26. S. Suresh, (1983) Engineering Fracture Mechanics, vol. 18, no. 3, pp. 577-593.

27. R. S. Piascik, (1990) PhD. dissertation, University of Virginia.

28. G. R. Yoder, L. A. Cooley, and T. W. Crooker, (1982) Scripta Met, vol. 16, no. 9, pp. 1021-1025.

29. R. W. Hertzberg, (1983) Deformation and Fracture Mechanics of Engineering Materials, 2nd ed. pg. 533, Wiley and Sons, New York, NY.

30. R. W. K. Honeycombe, (1984) The Plastic Deformation of Metals. 2nd ed., pg. 227. Edward Arnold Ltd., London. 
31. H. D. Dudgeon and J. W. Martin, (1990) International Journal of Fatigue, vol. 12, no. 4, pp. 253-258. 


\begin{tabular}{|c|c|c|c|c||}
\hline \multicolumn{4}{|c|}{ Table 1.} \\
\hline \hline \multicolumn{1}{|c|}{ MECHANICAL PROPERTIES of AA 8009 and TYPICAL IM Al ALLOYS } \\
\hline \hline ALLOY & $\mathrm{E}$ & $\sigma_{Y S}$ & $\sigma_{\mathrm{u}}$ & $\mathrm{e}_{f}$ \\
\hline \hline 8009 & $82 \mathrm{GPa}$ & $421 \mathrm{MPa}$ & $484 \mathrm{MPa}$ & $24.3 \%$ \\
$2024-\mathrm{T3}{ }^{1}$ & $73 \mathrm{GPa}$ & $345 \mathrm{MPa}$ & $483 \mathrm{MPa}$ & $18 \%$ \\
$2090-\mathrm{T} 8 \mathrm{E} 41^{2}$ & $78 \mathrm{GPa}$ & $552 \mathrm{MPa}$ & $589 \mathrm{MPa}$ & $9.3 \%$ \\
$2618-\mathrm{T} 651^{3}$ & $75 \mathrm{GPa}$ & $370 \mathrm{MPa}$ & $435 \mathrm{MPa}$ & $10 \%$ \\
\hline
\end{tabular}

1. Metals Handbook, vol. 1, 8th ed. ASM 1977.

2. K. T. V. Rso, W. Yu, and R. O. Ritchie, (1988), Met Trans A, vol. 19A, pp. 549-561.

3. Aluminum: Properties and Physical Metallurgy (1988), J. E. Hatch, ed. ASM. 


\section{PLAN VIEW OF STANDARD COMPACT TENSION SPECIMEN}

(ALL DIMENSIONS IN $\mathrm{mm}$.)

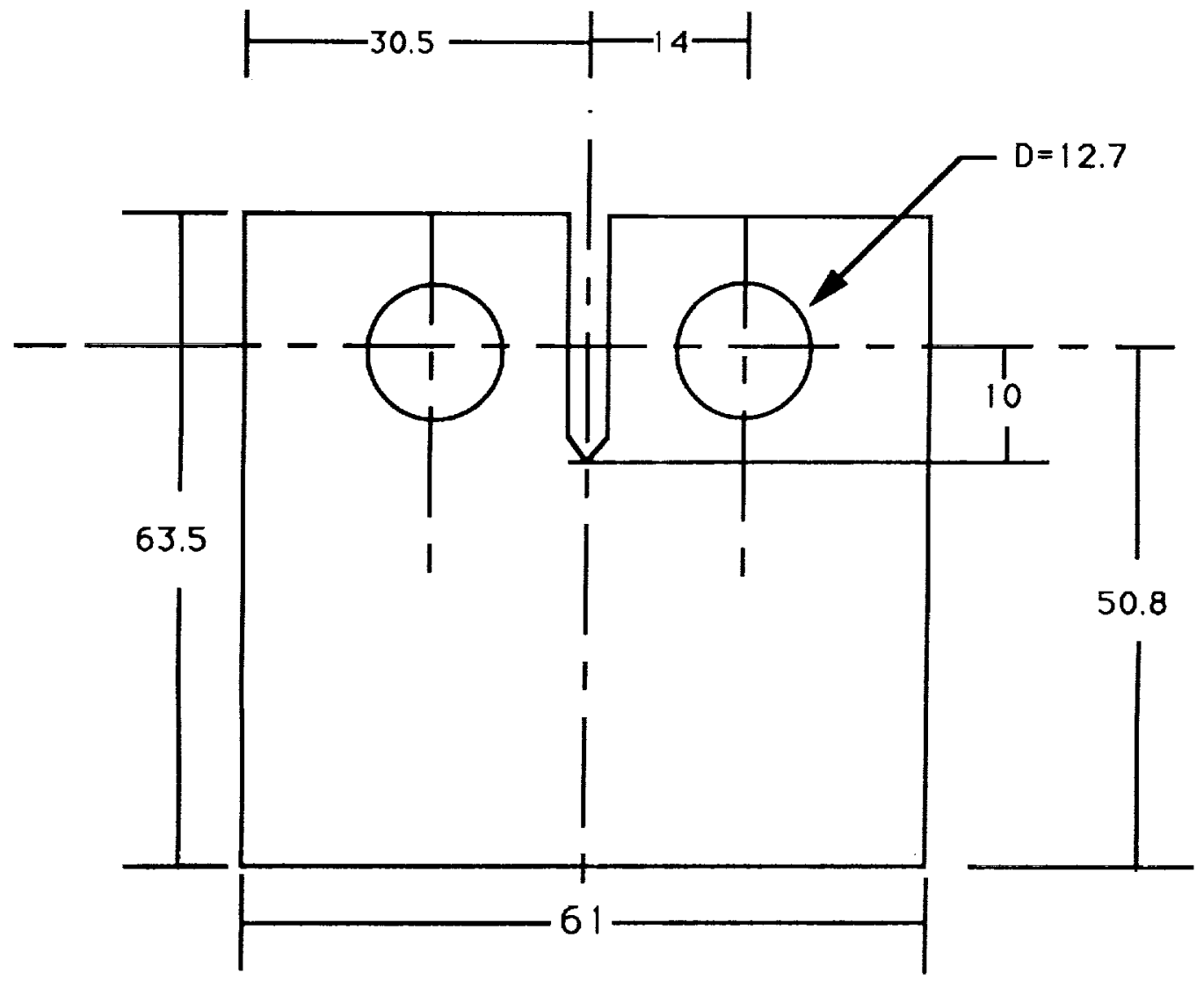

Figure 1. 


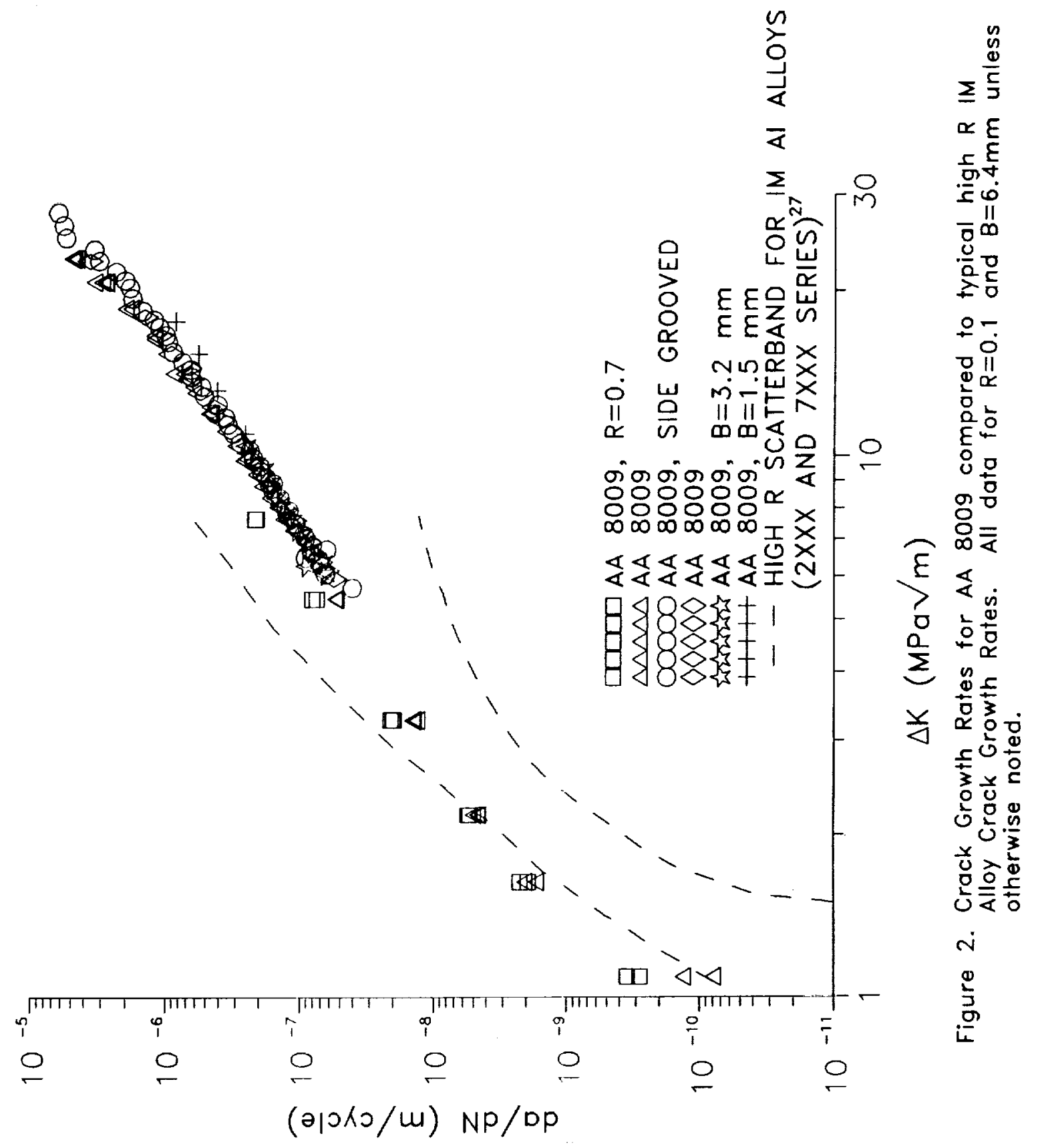




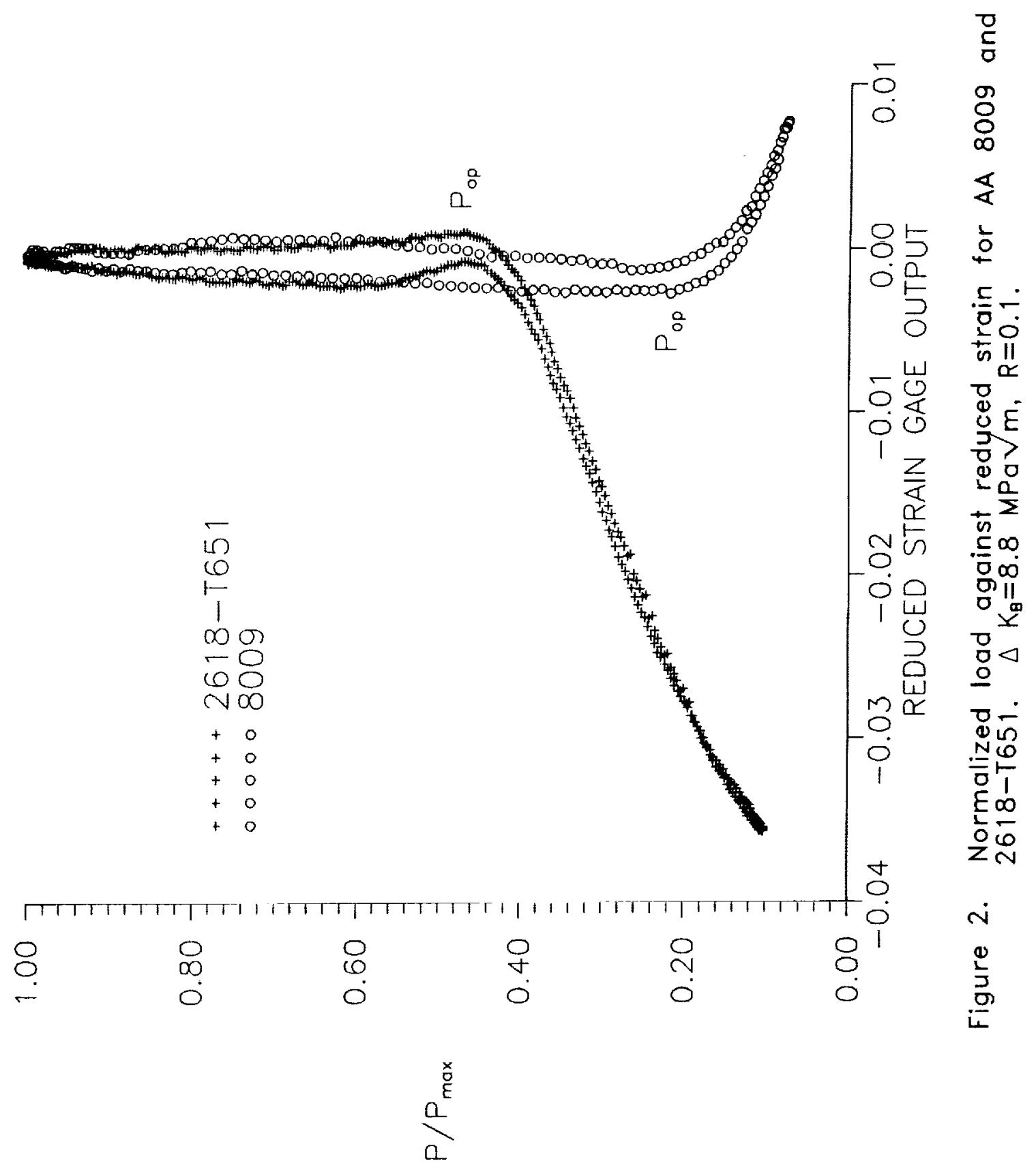




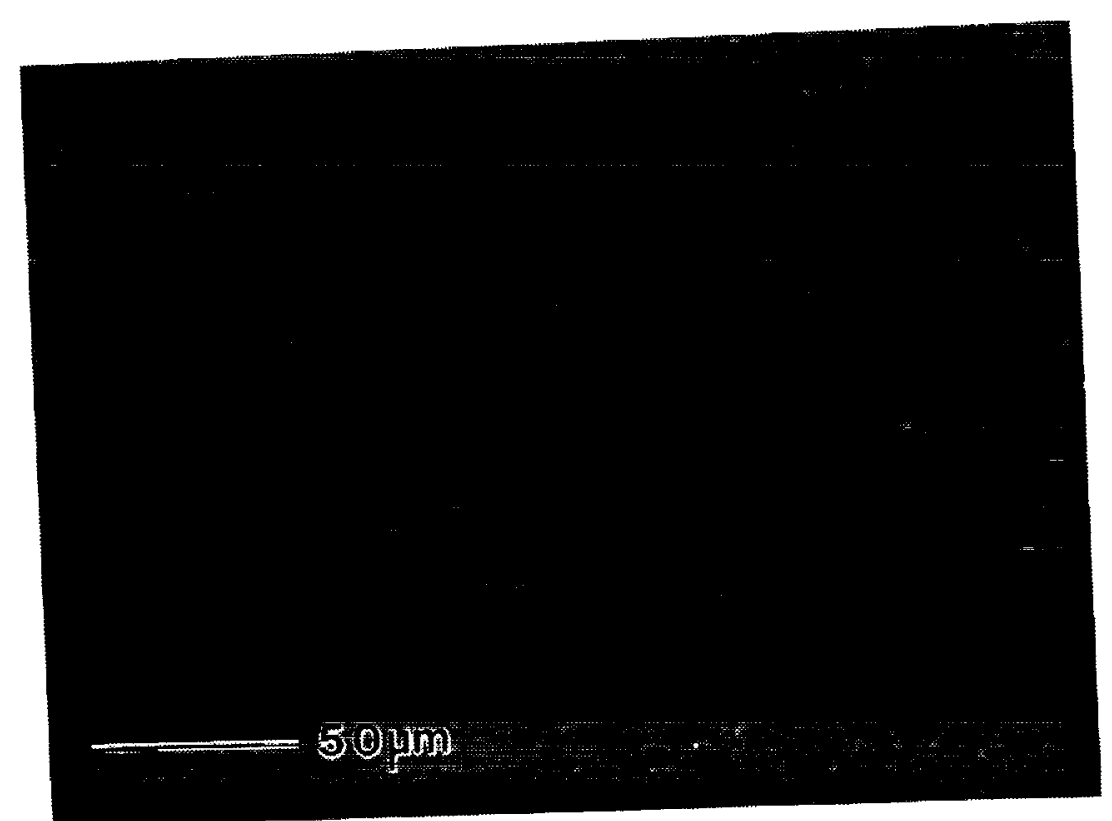

$4 a$.

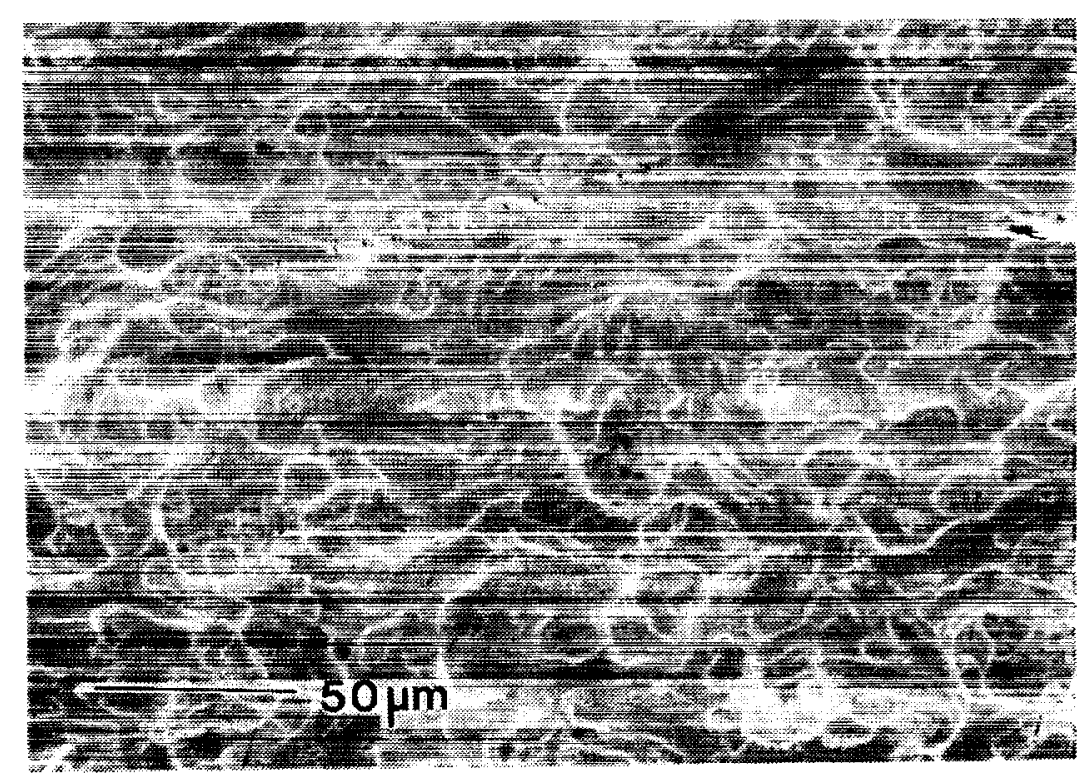

$4 \mathrm{~b}$.

Figures $4 \mathrm{a}$ and $4 \mathrm{~b}$. (a) Fatigue fracture surface of AA 8009 at $\Delta K=8.8 \mathrm{MPa} / \mathrm{m}, \mathrm{R}=0.1$ and, (b) fatigue fracture surface of AA 2618-T651 at $\Delta K=8.8 \mathrm{MPa} \vee \mathrm{m}, \mathrm{R}=0.1$. Surface roughness is significantly greater in AA 2618 than in AA 8009 at identical loading conditions. 


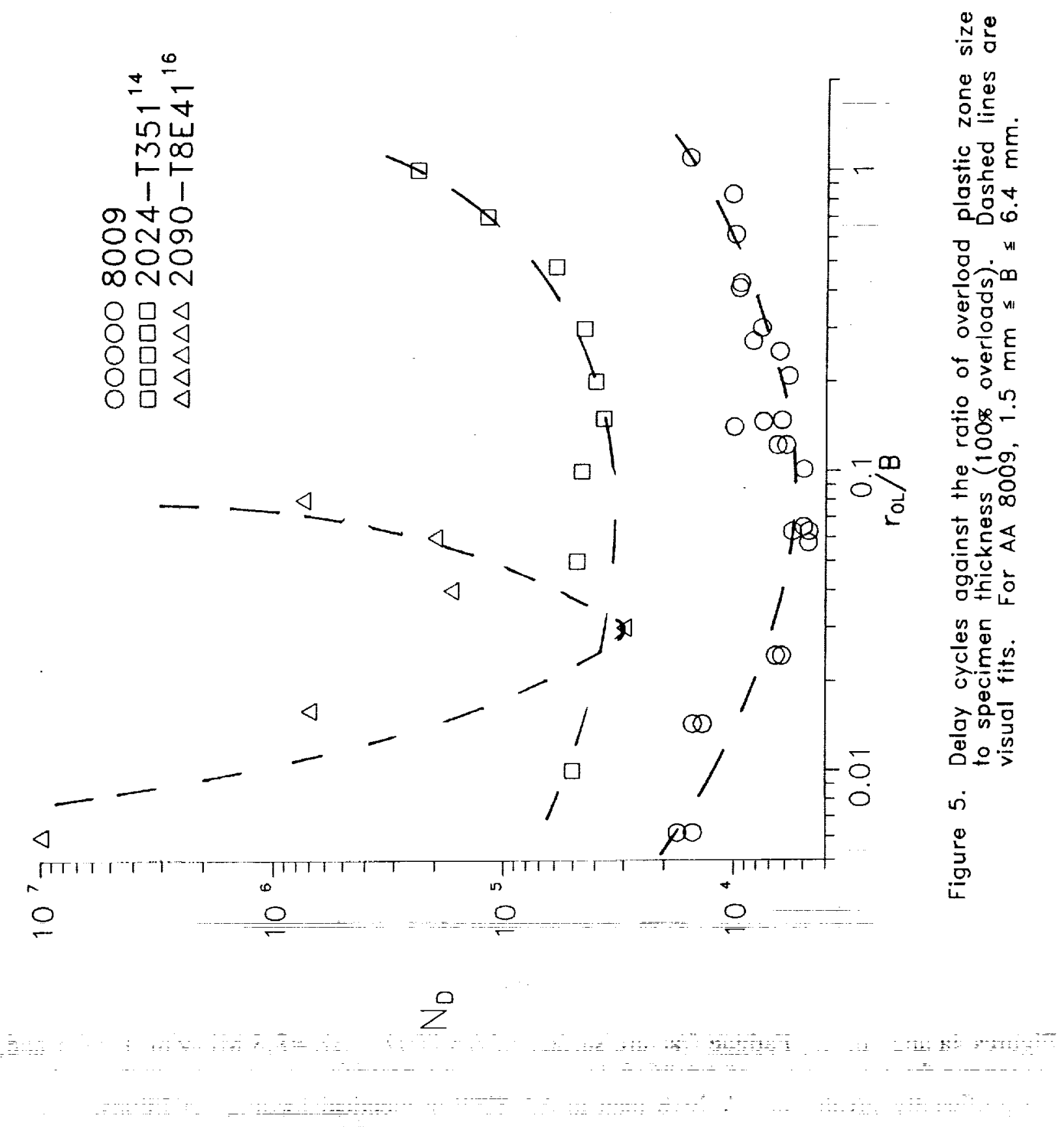




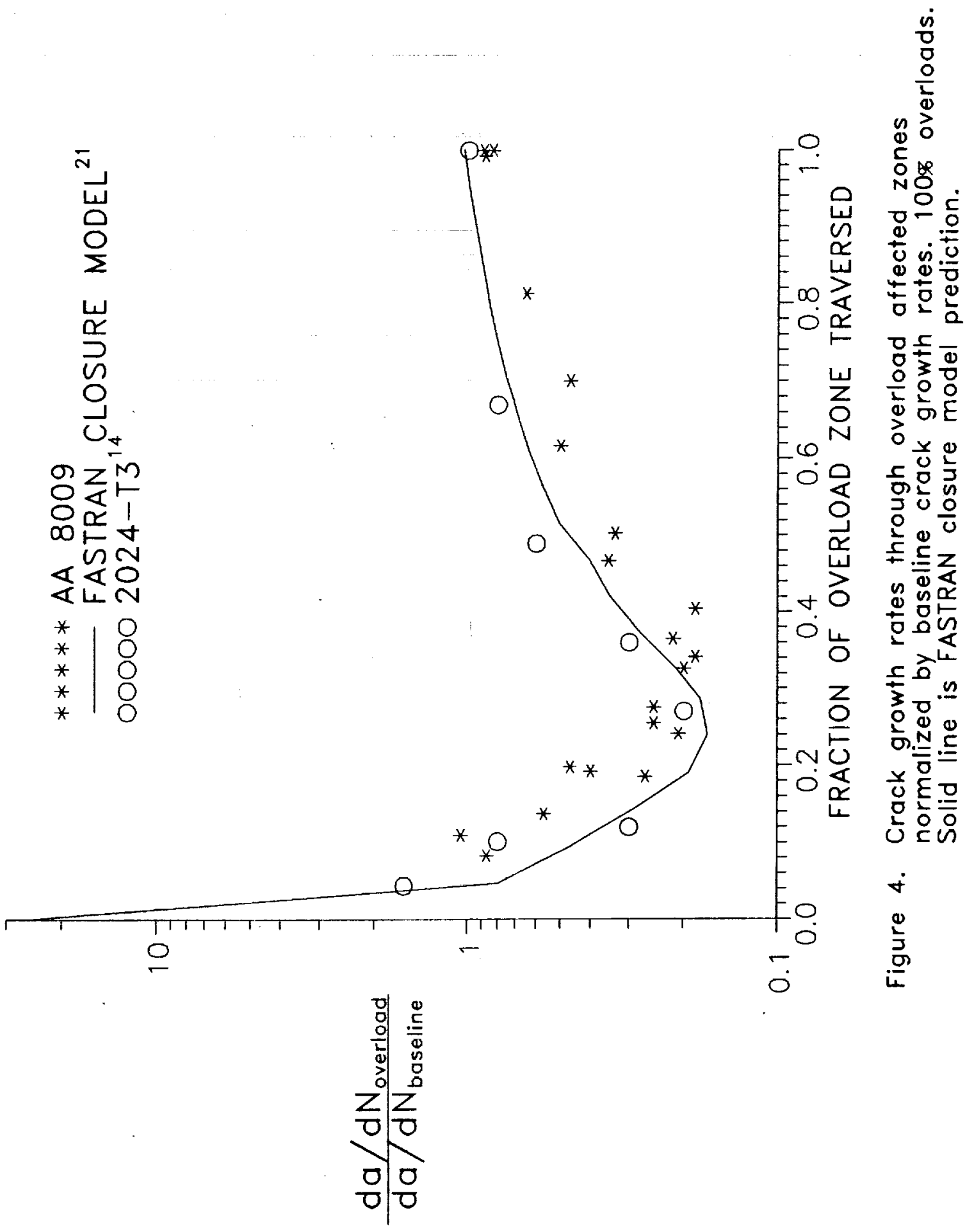




\section{ORIGINAL PAGE IS \\ OF POOR QUALTY}

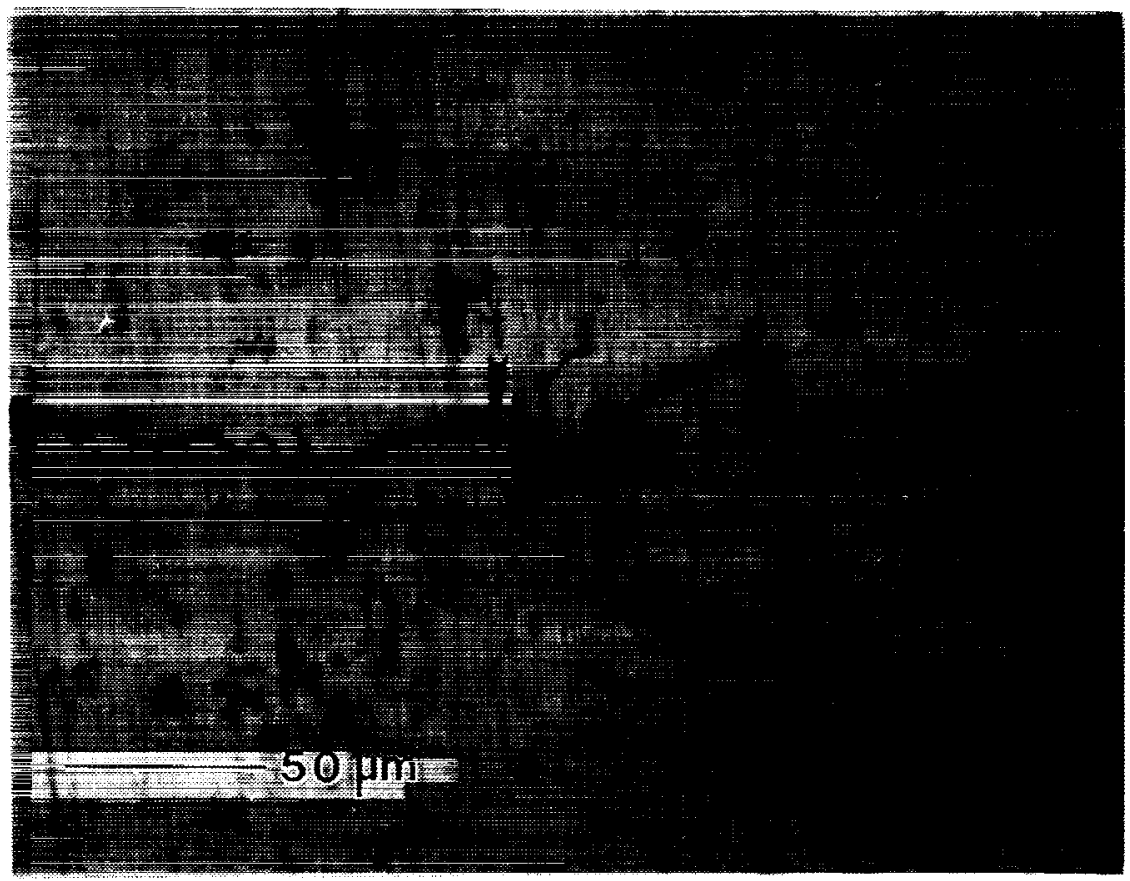

7a. AA 2618-T651 crack path at specimen surface. $\Delta \mathrm{K}_{B}=8.8 \mathrm{MPa} \vee \mathrm{m}, \mathrm{R}=0.1$. The crack growth direction is from left to right and the arrow indicates the point of application of a $100 \%$ overload.

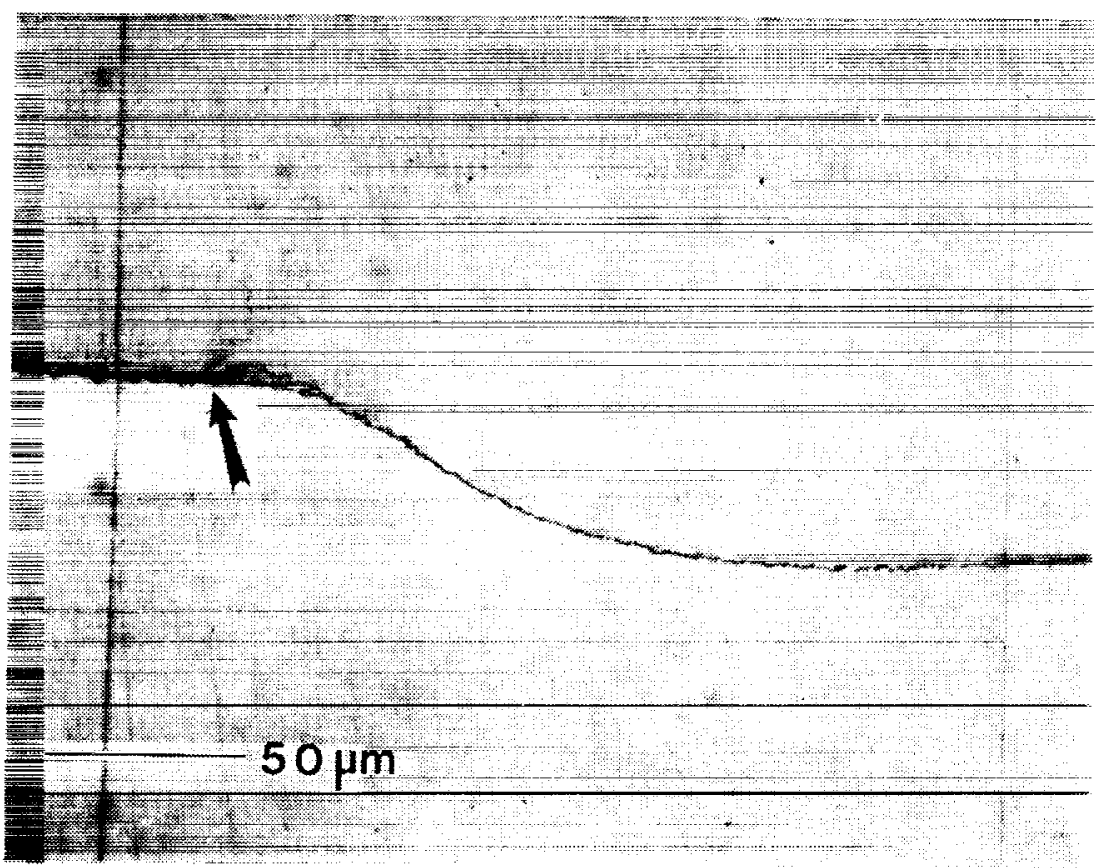

7b. AA 8009 crack path at specimen surface. $\Delta \mathrm{K}_{B}=8.8 \mathrm{MPa} / \mathrm{m}, \mathrm{R}=0.1$. The crack growth direction is from left to right and the arrow indicates the pooint of application of a $100 \%$ overload. 


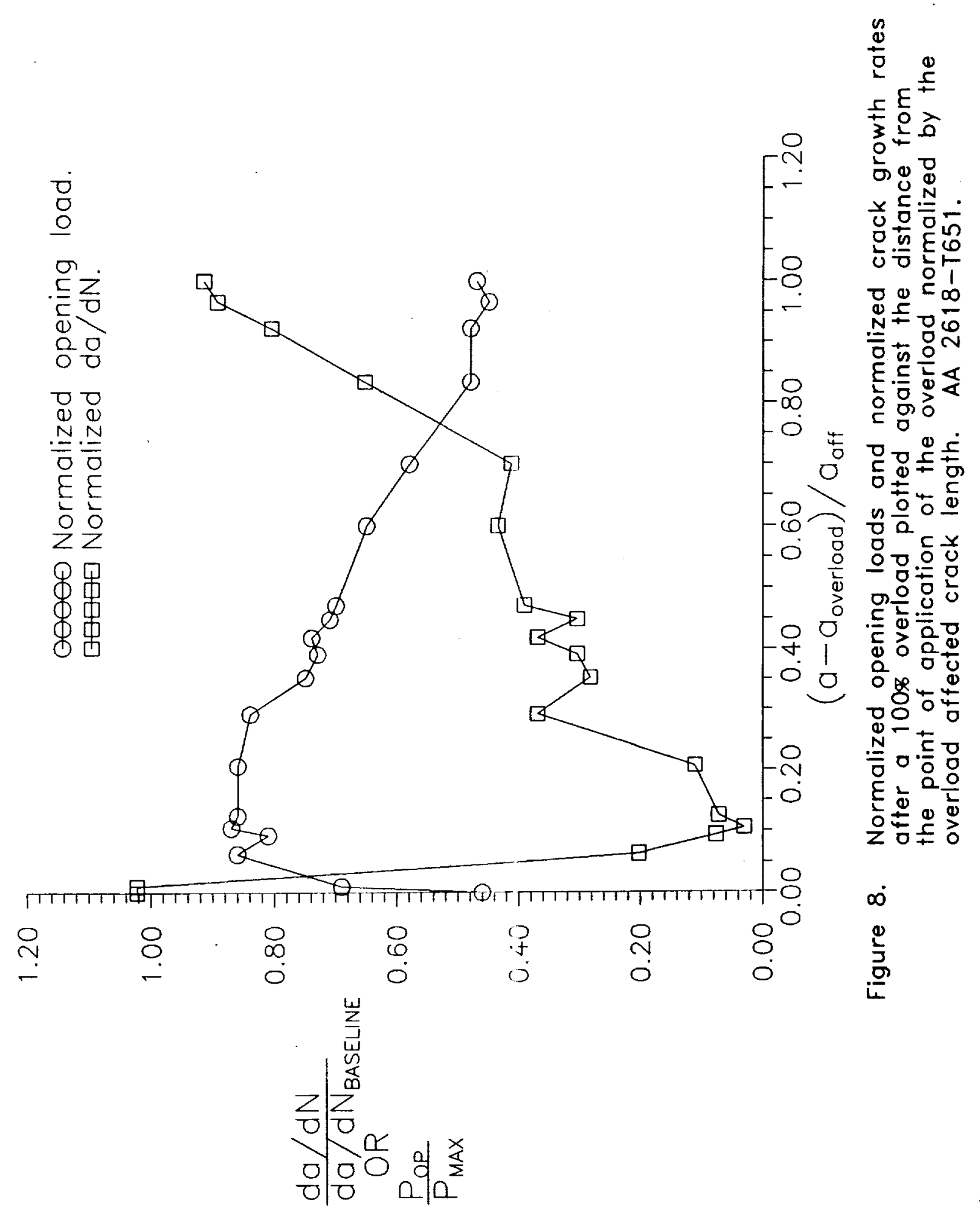




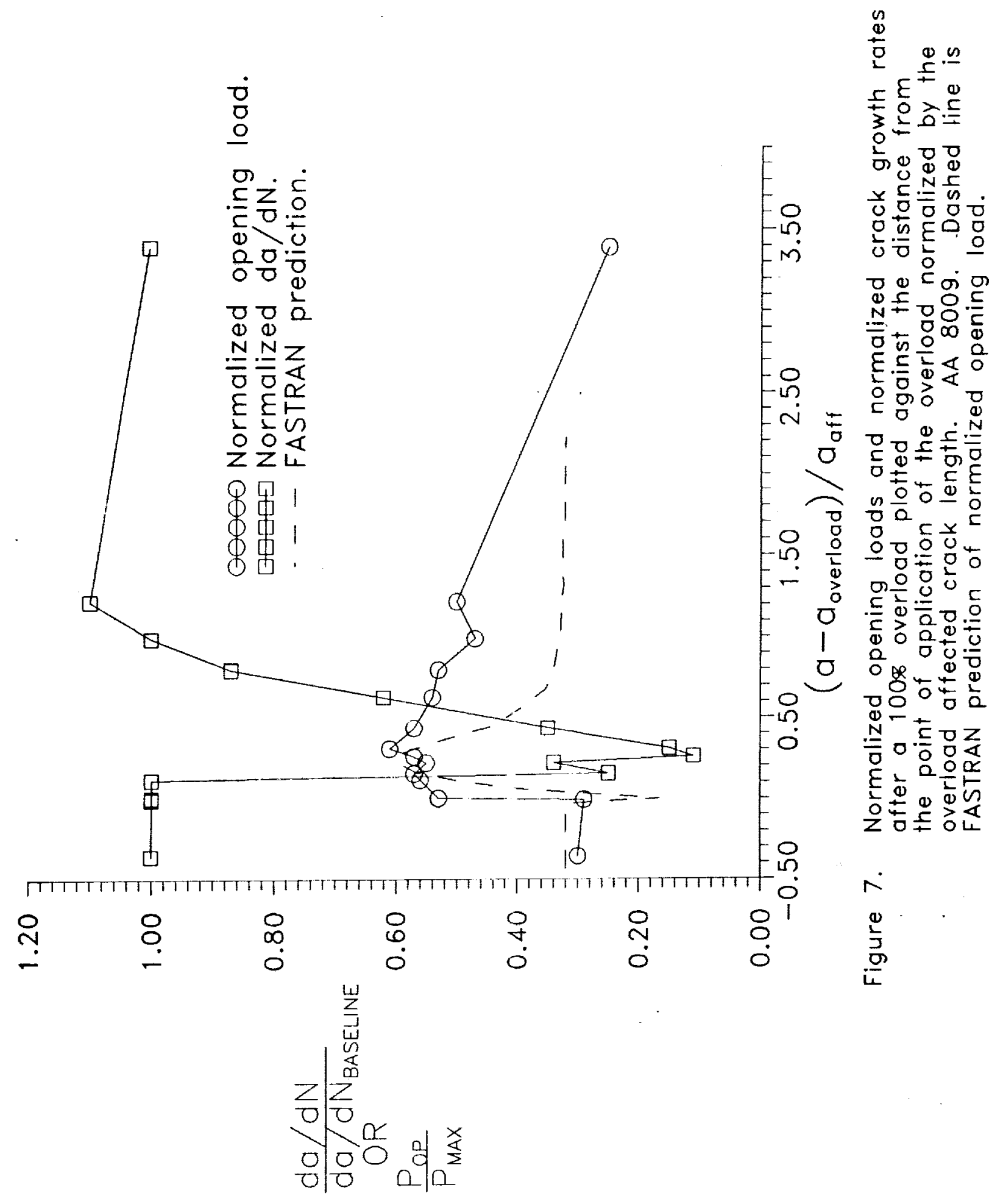




\begin{tabular}{|c|c|c|c|}
\hline \multicolumn{4}{|c|}{ Report Documentation Page } \\
\hline $\begin{array}{l}\text { 1. Report No. } \\
\text { NASA TM-104132 }\end{array}$ & 2. Government Accession No. & \multicolumn{2}{|c|}{ 3. Recipient's Catalog No. } \\
\hline \multicolumn{2}{|l|}{ 4. Titte and Subtitle } & \multicolumn{2}{|l|}{ 5. Report Date } \\
\hline \multirow{2}{*}{\multicolumn{2}{|c|}{$\begin{array}{l}\text { Constant Amplitude and Post-Overload Fatigue Crack } \\
\text { Growth Behavior in PM Aluminum Alloy AA } 8009\end{array}$}} & \multicolumn{2}{|c|}{ August 1991} \\
\hline & & \multicolumn{2}{|c|}{ 6. Performing Organization Code } \\
\hline \multirow{3}{*}{\multicolumn{2}{|c|}{$\begin{array}{l}\text { 7. Author(s) } \\
\text { A. P. Reynolds* }\end{array}$}} & \multirow{2}{*}{\multicolumn{2}{|c|}{ 8. Performing Organization Report No. }} \\
\hline & & & \\
\hline & & \multirow{2}{*}{\multicolumn{2}{|c|}{$\begin{array}{l}\text { 10. Work Unit No. } \\
\text { 505-63-50-04 }\end{array}$}} \\
\hline \multirow{3}{*}{\multicolumn{2}{|c|}{$\begin{array}{l}\text { 9. Performing Organization Name and Address } \\
\text { National Aeronautics and Space Administration } \\
\text { Langley Research Center } \\
\text { Hampton, VA } 23665-5225\end{array}$}} & & \\
\hline & & \multicolumn{2}{|c|}{ 11. Contract or Grant No. } \\
\hline & & \multirow{2}{*}{\multicolumn{2}{|c|}{$\begin{array}{l}\text { 13. Type of Report and Period Covered } \\
\text { Technical Memorandum }\end{array}$}} \\
\hline \multirow{2}{*}{\multicolumn{2}{|c|}{$\begin{array}{l}\text { 12. Sponsoring Agency Name and Address } \\
\text { National Aeronautics and Space Administration } \\
\text { Washington, DC } 20546\end{array}$}} & & \\
\hline & & 14. Sponsoring $A$ & Y Code \\
\hline \multicolumn{4}{|c|}{$\begin{array}{l}\text { 15. Supplementary Notes } \\
\text { *A. P. Reynolds, National Research Council Associate, NASA Langley Research Center, Hampton, VA } \\
23665\end{array}$} \\
\hline \multicolumn{4}{|c|}{$\begin{array}{l}\text { 16. Abstract } \\
\text { A recently developed, rapidly solidified, powder metallurgy, dispersion strengthened aluminum alloy, AA } \\
8009 \text {, was fatigue tested at room temperature in lab air. Constant amplitude/constant } \Delta \mathrm{K} \text { and single spike } \\
\text { overload conditions were examined. High fatigue crack growth rates and low crack closure levels } \\
\text { compared to typical ingot metallurgy aluminum alloys were observed. It was proposed that minimal crack } \\
\text { roughness, crack path deflection, and limited slip reversibility, resulting from the ultra-fine microstructure, } \\
\text { were responsible for the relatively poor da/dN- } \Delta \mathrm{K} \text { performance of } \mathrm{AA} 8009 \text { as compared to that of typical } \\
\text { IM aluminum alloys. }\end{array}$} \\
\hline \multicolumn{4}{|l|}{ i } \\
\hline $\begin{array}{l}\text { 17. Key Words (Suggesied by Author(s)) } \\
\text { AA } 8009 \\
\text { Fatigue } \\
\text { Overloads } \\
\text { Closure } \\
\text { Powder metallurgy }\end{array}$ & 18. Dist & $\begin{array}{l}\text { classified - Ur } \\
\text { ject Category }\end{array}$ & \\
\hline 19. Security Classif. (of this report) & 20. Security Classif. (of this pege) & 21. No. of pages & 22. Price \\
\hline Unclassified & Unclassified & 31 & \\
\hline
\end{tabular}




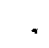

